\title{
Ecology of External and Internal Environment in the Socio-natural System
}

\author{
Vladimir Falko \\ Mytishchi Branch \\ Bauman Moscow State Technical University \\ Mytishchi, Russia 141005 \\ E-mail:vfalco@yandex.ru
}

\author{
Valentina Maykova \\ Bauman Moscow State Technical University \\ Mytishchi Branch \\ Mytishchi, Russia 141005 \\ E-mail: valmaykova@mail.ru
}

\author{
Eduard Molchan \\ Higher School of Folk Arts (academy) \\ Sergiyev Posad Branch \\ Sergiyev Posad, Russia 141300 \\ E-mail: ed.molchan2015@yandex.ru
}

\begin{abstract}
The notion of environment, relative to the category of system, includes not only the external environment (surrounding), but also the internal environment (context) of the system. However, the notion of internal environment in the system theories, social and ecological sciences is comprehended ambiguously or is lacking completely. The article provides comparative analysis of various internal environment conceptions as well as its correlation with the system and the external environment and justifies the inconsistency of identifying the internal environment with the composition of elements or with the relationship between the system constituents. The authors suggest their interpretation of the notion "internal environment (context)" as the substance of its elements, properties and relationship as well as the processes taking place outside the control of the system. We consider the content and essence of the notion "context" with regard to the social, natural and socio-natural systems, special peculiar features of the ecology of these systems, its environmental and contextual aspects. The ecology of the social and socio-natural systems external environment includes the relationship between the person and the society with natural and artificial environment and the issues of people's physical health. The state of the internal environment of these systems constitutes the subject of psychic ecology - care about spiritual life and human mental health, preservation of historical and cultural memory of the system, its subjectivity and ability to autopoiesis. The unity of the environmental and contextual approaches in ecology is particularly important amidst the crisis of the global socio-natural system.
\end{abstract}

Keywords-External environment (surrounding); internal environment (context); social system; socio-natural system; environmental and contextual aspects of the ecology; psychic ecology

\section{INTRODUCTION}

The study of ecological problems of human and social life involves considering the social systems in their cohesion with the environment as the combination of conditions and factors needed for the existence of people and society. In ecology and some social sciences as well as in the general systems theory the term "environment" is more often used in the narrow sense of the word - as the external environment (surrounding) for the respective system.

It is in this meaning, close to the latter, that the notion "environment" (Milieu in French) was introduced into philosophy and sociology by the French scientist and philosopher Hippolyte Adolphe Taine. In his environment theory this notion is defined as the world around us, mental, cultural, social environment where human activity takes place.

Along with this, the internal environment notion, contrary to the external environment category, which is sometimes called the context of the system, is also rather common in contemporary literature. Therefore, it is fair to say that the more general notion of environment includes not only external environment as surrounding, but also internal environment - the context of the system. But the notion of internal environment needs to be clarified, because in different sciences this term is comprehended ambiguously, if it exists at all.

The works [1][2] are devoted to the comparative analysis of different understandings of internal environment, its correlation with the system and the external environment and clarifying the internal and external environment notions. This article aims at disclosing the content and essence of the notions "environment" and "context" with regard to the general category of system and the notions of social, natural and socio-natural systems and finding out the specific aspects of the ecology of these systems' external and internal environments. 


\section{THE NOTIONS OF ENVIRONMENT AND SYSTEM}

As was mentioned above, the notion "environment" in contemporary literature is rather often identified with the external environment. For example, in the «Environmental Encyclopedia» its chief editor V. I. Danilov-Danilyan gives the following definition: "ENVIRONMENT syn. SURROUNDING, EXTERNAL ENVIRONMENT — in general systems theory, system analysis, cybernetics is considered as the notion additional to the notion "system" [3].

Article [3] provides the definition of environment, which was given by the American systems analysts Arthur D. Hall and Robert E. Fagen for the system environment: "For a given system the environment is the set of all objects a change in whose attributes affect the system and also those objects whose attributes are changed by the behavior of the system". The notion of system is defined here as "a variety of objects in conjunction with the relationships between the objects and between their attributes (properties)" [4].

Asking the natural question: "When is the object considered to belong to the environment, and when does it belong to the system?", Hall and Fagen do not see an objective criterion for the answer. They conclude that the ways to divide this world into two multitudes - the system and the environment - are rather random and depend on the subject's intentions.

This conclusion seems to be based on the negation of the ontological status of objectively-actual existence of systems and recognizing them as only constructs-instruments. In this regard, A. I. Uyomov and his followers repeatedly noted that "the relativity of the system to the selected (of course, subjectively selected!) concept does not necessarily have to mean definitely ideal Thuswise only in the form of a construct Thuswise existence of the system itself" [5]. In other words, though the things belonging to the system depends on the subject, there exist objective criteria of systematicity.

The discoveries of the last decades of the $20^{\text {th }}$ century testify in favor of the objectively-actual existence of the system and its ontological status. They include selforganization phenomena in nature and autopoiesis mechanisms as the self-reproduction capabilities of biological and social systems and their ability to preserve their cohesiveness. That is why the objective criterion for distinguishing between the system and the environment is inclusion or non-inclusion of the objects into the autopoiesis mechanism of the corresponding system [6].

If the objects' belonging to the environment or system happens to be difficult to identify, then the clearer notion allowing us to refer particular things to one of these multitudes is the notion of controllability. The objects, their properties and relationship as well as the processes controlled in their behaviour by the system self-reproduction centers are included into this system, and those which are not controlled by its self-organization and self-management mechanisms refer to the environment - either external or internal [7].
The other additory attribute of the environment, created by the random combination of things, is a non-system impact on the system, which is a lack of including the objects, processes, their relationship and properties of the surrounding influencing on it into this system. Concurrently, one should distinguish the nature of the environmental impact on the system and its constituents as conditions from the control actions of the system on its sub-systems and elements. On the other hand, not only the controlling subsystem, but also its other constituents can control certain system parameters. In order to do that, they must possess autonomous or independent internal organization [8].

\section{THE NOTIONS OF EXTERNAL OR INTERNAL ENVIRONMENTS OF THE SOCIAL SYSTEM}

The papers quoted above and many other publications do not deal with the internal environment notion. The relationship within the system, according to Hall and Fagen, as well as many other authors, does not form its environment, because they connect the elements of the system with each other and create the system. The elements themselves, along with their properties and relationship, entirely belong to the system.

There is also such point of view that the internal environment is a combination of intrasystemic situational factors comprising the characteristics of the system's composition and structure - the state and conditions of the elements functioning, the relationship and connections between them. The internal environment in this sense belongs to the system, unlike the external environment as the non-system surrounding. The interpretation of the internal environment as the internal constituents belonging to the system is inherent to the organization theory, management and other social conceptions. For instance, in the fundamental textbook "The Foundations of Management" the internal environment of the organization, constituting an open socio-technical system created by people, is defined as its internal variables — "situational factors existing inside the organization... The purposes, structure, tasks, technologies and people refer to the main internal variables of the organization" [9].

Understanding the internal environment as the surrounding of sub-system can be found in the theories of the social functional systems, particularly political system theory. In the world-wide review of comparative political studies Gabriel A. Almond and his co-authors consider political system in the internal and external environment [10]. Internal environment is formed here by the other functional subsystems of the society and non-political relations within the borders of the state: economics, culture, social structure etc., while external environment is composed by foreign countries [11]. Therewith the elemental composition, the structure and functions of the political system are not included into the notion of its internal environment.

Karl Wolfgang Deutsch discovers similar distinction between internal and external environment within the confines of the surrounding in his information- cybernetic model of political system. At the "input" of the political 
system the "receptors" (perceiving structures including information services) accept information from the internal (nearest) and external (international) environment [12].

It is easy to see that when incorporating the internal environment into the system composition this entails the surrounding of elements and sub-systems, which is their external environment. Thuswise, the famous Canadian political system theorist David Easton notes that political life as a system should be considered in the physical, biological, social and psychological surroundings [13].

Understanding internal environment as the relationship between the sub-systems or elements seems to be wrong since the attribute of the environment must be the non-system impact on the system. The insight corresponding to this requirement and shared by the authors of this work consists in interpreting the internal environment as a context, a number of impacts on the system by its elements. In this respect, the internal nature and structure of elements is not included into the systems organization of the society.

A look at the internal and external environment as a multitude of non-system factors is encountered in the international relations theory. The textbook by P.A. Tsygankov gives the following definition: "Internal environment (context) is a number of compulsions exerted by the elements onto the system. ...Environment, unlike structure, is a number of compulsions of a non-system kind" [14].

The notion of the non-system status of internal environment becomes clear when the latter is interpreted as the environment formed by the objects and relations inside the elements and not between them. The subelementary nature of the deeper state objects is not accountable to their ambient system and its sub-systems.

The distinctive characteristic of the external environment is considered to be an existence of its contact with the system, that is to say, any spatial non-system relationship and corresponding impacts refer to the external environment. In this case the environment and system spaces are parts of the same space: physical - for material things, ideal - for mathematical or logical objects, mental - for internal things of our consciousness, social - for the elements of the society etc. [15].

A peculiar feature of the internal environment (context) is a lack of touch-down relations and a presence of the relations of penetrating inside the elements and states of the system. In other words, the things, forming the internal environment, are non-spatial: they do not occupy any place in space, the part of which is occupied by the system. For that reason, the forms of the system's internal environment existence include, in particular, time relations. In accordance with this form of existence, the objects, forming the system's context, can have historical nature (the states of the system, cultural memory and the historical time itself) or mental (human soul, psyche, social psychology). Mental and historical objects have non-spatial forms of existence [16].

The internal environment, by definition uncontrolled by the system, can only be transcendent or transcendental, lying beyond the bounds of the empirical observation, informational reflection and system self-description. Otherwise speaking, the internal environment cannot be expressed by the text and can be conceived only as a context. That is why the systems theory abstracts from the internal substance of the elements, contemplating them as indivisible sub-systems.

Time and history can take on the role of the system's context if they are not the subjects of system analysis. A different situation arises with the reflected, measured or counted time that is objectified and mapped upon the space of a certain nature. The external environment and the context of historical and natural-historical processes, considered in the diachronic aspect of system analysis, appear as its subject, reflected in spatial structures. Therefore for the respective systems it is typical to have the external environment and embracing systems. So, for instance, for one or another stage of historical development the external environment is formed by preceding and subsequent stages, and the embracing systems are epoch, historical period and era [17].

Apart from the time context, the system's external environment is formed by the things possessing timeless forms of existence, notably ideal and informational objects, and also super-temporal forms, that is spiritual phenomena. For the spatial, time relations as well as non-spatial and timeless ones determinacy is typical, it is inherent to all kinds of existential being including the sharpness of borders. The spiritual context is characterized by freedom which should not be mixed with indeterminacy. Responsibilities, without which freedom cannot exist, transforming the subject's activity, infuse determinacy and austerity to the spiritual relations. The sharpness of borders in the spiritual environment resembles the horizon of moral choice, dividing good and evil, or the delimitation of the external liberties of an individual established by the legal norm.

The indeterminacy of the environment parameters and its borders with the system is discovered in virtual reality, which can form both the external environment and the system context. The impact of the virtual environment components on the system remains safe for its existence to a certain extent of impact and under the condition of preserving the operational isolation of the system, providing its self-referentiality. Otherwise, chaotic state of the environment may destroy the order ensuring the system's existence. Virtuality can be created not only by chaos, but also by spiritual reality of the internal environment open to the transcendent world and containing supreme values, thanks to which the system can pass into the state of higher degree of order.

\section{ECOLOGICAL PROBLEMS OF THE EXTERNAL AND INTERNAL ENVIRONMENTS OF THE SOCIAL AND SOCIO- NATURAL SYSTEMS}

The ecology of the social system's external environment comprises the relationship of the individual and society with the natural, agro-industrial and information-urbanistic environment as well as the issues of human physical health. The problems existing in these areas constitute the subject 
matter of social, industrial ecology and some other directions of science and practice. Creating efficient and safe technologies, establishing ethical control over the development and application of up-to-date technological waves, improving ecological education and nurturing, consolidation of moral and law principles and norms of natural resource management in the environment codes, harmonization of global processes are significant and promising research and development trends in the aims of social ecology [18].

It is required to specify the subject-matter of the socionatural system's external environment ecology. This system consists of biosocial human nature and part of natural environment directly included into the area of human and social practical activity. Its external environment is that part of natural habitat, which constitutes actual conditions and factors of human and social life and activity and undergoes indirect influence of socio-natural system. Within this space - a fuzzy and expansionary event horizon, where the humanity interacts with the universe and the structural levels of nature organization go into depth - the environmental problems arise. They are particularly the issues of the ecology of outer space distant regions. The interaction with these regions, its type, extent and scales require investigations and forecasting with the application of new methods and means of perception, the development of exoplanets research, the tasks of developing nature-friendly technologies.

The internal environment state of social and socionatural systems is a subject-matter of the psychic ecology care about spiritual life and human mental health, preservation of historical and cultural memory of humankind and the system, its subjectivity and ability to autopoiesis, moral and sociocultural control over the convergent technologies of human perfection, creation and use of the artificial intelligence [19]. The essential directions in these areas include the development of ecological morality, ecoesthetics, bioethics, legal confirmation of the wild-life's and natural ecological systems' rights. It is necessary to investigate the frontier areas of wildlife and inanimate nature, biological and social forms of mental and spiritual human and social life, possible ways of global evolution, organization, consequences of human intervention into the mechanisms of life and reason advent, the threats of involution and degradation of human nature. It is of great interest to research and solve the problems of exosociology and exoethics.

Is there a limit of cognizability and practical human exploration of the unclosing and concealed from us depths of the universe? In connection with this question it is interesting to consider the components of the social system's internal environment, which refer to the highest levels of hierarchy constructed in the ontologically significant metatheory of systems of Kenneth Ewart Boulding. It is level VII, at which a person is considered as a system, VIII - the level of social system as a set of roles performed by people, and level IX, comprising the transcendental systems. The first two levels have been investigated by means of the systematic approach for a relatively long time. The last level of the system hierarchy is inconceivable according to K. Boulding: "There are, however, unanalyzable absolutes and certain relationship. A day will come for people when no one will be allowed to ask questions that cannot be answered" [20].

It seems, however, that the potential of the transcendental approach is far from exhausted, and without its rereading, contemporary rethinking it is impossible to construct a new systems theory of the highest level of hierarchy. Moreover, without developing the theory of transcendently open systems it is impossible to stand up against those destructive trends, which are observed in the spiritual environment of the social system and in the system itself.

\section{CONCLUSION}

In the further development of investigating the external and internal environments of social and socio-natural systems and ecological practice in these fields mutual complementation and penetration of the environmental and contextual approaches in ecology, general systems theory and social sciencies is expected [21]. Research and development of such problems of the collective consciousness cohesiveness as environmental consciousness are considered to be prospective [22][ 23].

The center for the mutual intersection of various directions of scientific and philosophical research in these fields is human ecology, and the main ways to solve the global ecology problems of the external and internal human and social environments are destined to become the development and expansion of interpersonal communication and spiritual perfection of a human being.

Social movements, intellectual and cultural communities, political willpower of national leaders must play a critical role in achieving positive results.

\section{REFERENCES}

[1] Falko V. I. Spiritual and temporal context as the internal environment of the social system within the conditions of world crisis. Proc. of the International Scientific Conference "Humanitarian dimensions of crisis: the experience of Russia, Switzerland and the European Union". Moscow, December 10-12, 2009. Moscow, MAKS Press Publ., 2010, pp. 194-217.

[2] Falko V. I. Internal environment of the social system as object of cultural politics. Cultural politics and personal culture: monographic collection. Moscow, MGUKI Publ., 2013, pp. 18-27.

[3] Danilov-Danilyan V. I. Environment. Ecological encyclopedia. In 6 volumes. Vol. 6. Moscow, Entsiklopediya Publ., 2013, p. 119.

[4] Hall A. D. and Fagen R. E., Definition of System. General Systems, vol. 1, 1956, pp. 18-28.

[5] Tsofnas A. Yu., ed. Parametric general systems theory and its applications: Collection of works, dedicated to Prof. A. I. Uyomov's $80^{\text {th }}$ anniversary. Odesa, Astroprint Publ., 2008, p. 6.

[6] Lebedev S. A. The Structure of Scientific Rationality // Voprosy filosofii. 2017. № 5. Pp. 66-79.

[7] Gubanov N. I., Gubanov N. N. Course of lectures in philosophy of science // Herald of the Russian Academy of Sciences. 2015. V. 85. № 10. Pp. 946-948. DOI: 10.7868/S0869587315100059.

[8] Gubanov N. I., Gubanov N. N. Subjective reality and space // Voprosy filosofii. 2015. № 3. Pp. 45-54. 
[9] Mescon M. H., Albert M., Khedouri F. Management. New York, Harper \& Row, 1988. 777 p. [In Russ.: Mescon M. H., Albert M., Khedouri F. Osnovy menedzhmenta. Moscow, DELO Publ., 2007, p. $76]$.

[10] Almond G. A., Powell G. B., Strom K., Dalton R. J. Comparative politics today: a world view. 8th ed., New York, Pearson, 2004, 808 p.

[11] Suzdaleva T. R. Migratory processes in the context of geopolitics // Vestnik Tomskogo gosudarstvennogo universiteta-Filosofiyasotsiologiya-politologiya-Tomsk state university journal of philosophy sociology and political science. 2016. № 3 (36). Pp. 237244. DOI: $10.17223 / 1998863 X / 35 / 25$

[12] Deutsch K. W. The nerves of government: models of political communication and control. New York; London, The Free Press, $1966,316 \mathrm{p}$.

[13] Easton D. The Analysis of Political Structure. New York, Routledge, 1965.

[14] Tsygankov P. A. International relations theory. Moscow, Gardariki Publ., 2007, p. 193.

[15] Gubanov N. I., Gubanov N. N. The role of mentality in the development of society: sociocultural hypothesis // Vestnik slavianskikh kultur-bulletin of slavic cultures-scientific and informational journal. 2017. Vol. 43. № 1. Pp. 38-51.

[16] Gubanov N. I., Gubanov N. N. Mentality: the nature and functioning in society // Voprosy filosofii. 2013. № 2. Pp. 22-32.

[17] Komissarov I; Nekhamkin V. The Models of Historical Cognition: Current Status and Prospects of Development // Istoriya-Elektronnyi nauchno-obrazovatelnyu zhurnal. 2017. Vol. 8. Issue 2. DOI: 10.18254/S0001779-5-1

[18] Oseledchik M. B., Ivlev V.Yu., Ivleva M.L. Knowledge as a nonequilibrium dynamic system // "Proceedings of the $20172^{\text {nd }}$ International Conference on Contemporary Education, Social Sciences and Humanities". (ICCESSH 2017). Part of the series ASSEHR. Moscow, Russia. V/124. Pp.1-5.

[19] Inozemtsev V. A., Ivlev V.Yu., Ivleva M.L. Artificial intelligence and problem of computer representation of knowledge // "Proceedings of the $20172^{\text {nd }}$ International Conference on Contemporary Education, Social Sciences and Humanities". (ICCESSH 2017). Part of the series ASSEHR. Moscow, Russia. V.124. Pp.1151-1157.

[20] Boulding K. General Systems Theory - the Skeleton of Science, General Systems, 1956, vol. 1, pp. 11-17. [In Russ.: Boulding K. General Systems Theory - Skeleton of Science // Nikanorov, S.P. Theoretical and system constructs for conceptual analysis and design. Appendix 2. Moscow, 2008, p. 279].

[21] Falko V. I. Environmental ethics and spiritual ecology in the globalization era. Moscow State Forest University Forestry Bulletin LESNOY VESTNIK, 2011, no. 2(78).

[22] Maykova V. P. Gnosiological and methodological problems of forming the public consciousness in the postindustrial age. Moscow, Moscow State Forest University Publ., 2012, 177 p.

[23] Maykova V. P. Socio-philosophical problems of collective consciousness dynamics in modern-day Russia. Moscow, Moscow State Forest University Publ., 2013, p.196 